\title{
Opportunities for Reasoning: Digital Task Design to Promote Students' Conceptions of Graphs as Representing Relationships between Quantities
}

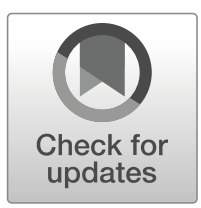

\author{
Heather Lynn Johnson ${ }^{1}$ (D) - Evan D. McClintock ${ }^{1} \cdot$ Amber Gardner $^{1}$
}

Published online: 28 February 2020

(C) The Author(s) 2020

\begin{abstract}
We posit a dual approach to digital task design: to engineer opportunities for students to conceive of graphs as representing relationships between quantities and to foreground students' reasoning and exploration, rather than their answer-finding. Locally integrating Ference Marton's variation theory and Patrick Thompson's theory of quantitative reasoning, we designed digital task sequences, in which students were to create different graphs linked to the same video animations. We report results of a qualitative study of thirteen secondary students (aged 15-17), who participated in digital, taskbased, individual interviews. We investigated two questions: (1) How do students conceive of what graphs represent when engaging with digital task sequences? (2) How do student conceptions of graphs shift when working within and across digital task sequences? Two conceptions were particularly stable - relationships between quantities and literal motion of an object. When students demonstrated conceptions of graphs as representing change in a single quantity, they shifted to conceptions of relationships between quantities. We explain how a critical aspect: What graphs should represent, intertwined with students' graph-sketching. Finally, we discuss implications for digital task design to promote students' conceptions of mathematical representations, such as graphs.
\end{abstract}

Keywords Digital task design · Variation theory · Quantitative reasoning · Graphs

By means of digital technology, students have opportunities to sketch and interpret dynamic graphs linked to video animations (Kaput 1994; Kaput and Roschelle 1999; Schorr and Goldin 2008). Yet, such opportunities are only a starting point. Instead of promoting reasoning, student interactions with digital technology may focus on skills and recall (Kitchen and Berk 2016). We developed digital task sequences that center on

Heather Lynn Johnson

heather.johnson@ucdenver.edu

1 University of Colorado Denver, Denver, CO, USA 
students' reasoning and exploration, rather than answer-finding. A key aim was for students to expand their conceptions of what is possible for graphs to represent. Integrating different theories, we designed and conducted a study investigating secondary students' engagement with the task sequences.

Student difficulties with graphs have presented an enduring challenge. Prior to the pervasiveness of digital technology, researchers documented them via the interpretation of graphs. Three key difficulties included students' interpretations of graphs as representations of (1) characteristics of a physical object (e.g. a hill) (Clement 1989; Leinhardt et al. 1990), (2) a literal path of an object (e.g. a walk from home to school) (Bell and Janvier 1981; Kerslake 1977) and (3) elapsing time, even when neither variable was time-dependent (e.g. mass vs volume) (Janvier 1998).

Although digital technology has brought many affordances (Drijvers 2015; Lobato et al. 2019) both university and secondary school students continue to have difficulties with graphs. Moore et al. (2019) found that university mathematics students' perceptual interpretations of graphs can account for their struggles, while Vitale et al. (2019) found that the designer's goal for a task can impact secondary science students' focus on relationships represented in graphs. By conceiving of graphs as representing relationships between quantities, students could interpret trends and issues represented by graphs encountered in their daily lives.

We employ a dual approach to digital task design: to engineer opportunities for students to conceive of graphs as representing relationships between quantities and to foreground students' reasoning and exploration, rather than their answer-finding. To illustrate this, consider a video animation of a toy car moving along a path, with a small shrub positioned to the lower right of the toy car's path (Fig. 1). Given a co-ordinate plane with axes labeled 'total distance traveled' and 'distance from shrub', students can sketch a graph to represent the situation.

A teacher or researcher may tell students that the graph should represent a relationship between the different distances. Yet students can have a wide range of conceptions of what their graphs represent. For one student, the graph may represent the literal path of the car. For another, the graph may represent the changing length of a stretchable cord connecting the car and the shrub. Rather than attempting to fix or replace student conceptions, we
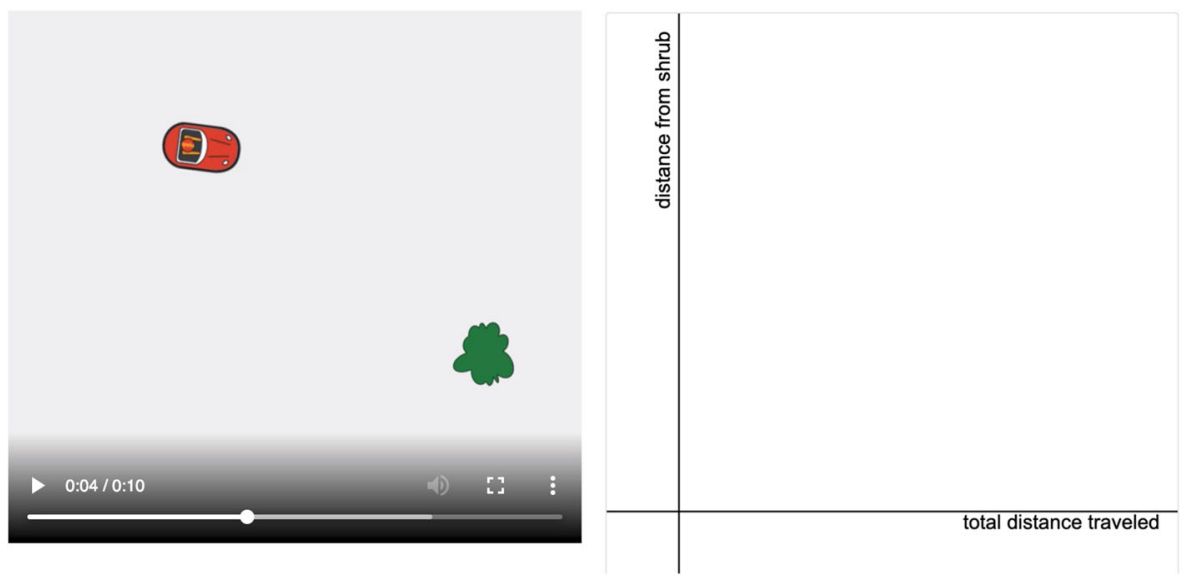

Fig. 1 Toy Car video animation and linked co-ordinate plane 
instead acknowledge their viability. Accordingly, we foster opportunities for students to shift their existing conceptions, through their own goal-directed activity.

In this article, we report on results of a qualitative study of thirteen secondary students (aged 15-17), who interacted with digital task sequences during a series of three individual, task-based interviews. We developed the digital task sequences in a freely available, web-based platform - Desmos - in collaboration with Dan Meyer, its Chief Academic Officer. The task sequences incorporate video animations with opportunities to sketch and interpret different graphs, each representing the same relationship between attributes depicted in the animation. We investigate two questions: (1) How do students conceive of what graphs represent when engaging with digital task sequences? (2) How do student conceptions of graphs shift when working within and across digital task sequences?

\section{Integrating Theories for Design and Analysis}

In our design and analysis, we integrated two theories: Patrick Thompson's theory of quantitative reasoning (Thompson 1994, 2002, 2011) and Ference Marton's variation theory (Marton 2014; Kullberg et al. 2017). Drawing on Thompson's theory, we explain how students could conceive of these attributes in a specialized way - as capable of varying and being possible to measure. Drawing on Marton's theory, we explain how students could discern graphs as representing a relationship between attributes depicted in a video animation. In each of these theories, the researchers acknowledge that a student's perspective is different from a researcher's perspective and explain how they address a juxtaposition of these different perspectives. Thompson (1994) states that calling an attribute a quantity depends on a person's conception of that attribute. Similarly, Marton (2014) states that adults cannot expect children to discern something that adults discern in the world, just because adults tell them or show them. By employing theories that foreground the student perspective, we take into account differences among the goals of designers, students and researchers.

Thompson $(1994,2011)$ explains students' mathematical thinking in terms of students' conceptions of attributes. If a student can conceive of the possibility of measuring some attribute, then that attribute is a quantity for that student. For example, a student may view a video animation of Cannon Man, who is shot vertically into the air, then comes back down to the ground (Fig. 2). In this situation, there are many different attributes, one of which is Cannon Man's total distance traveled - both up and down. If a student conceives of the possibility of measuring Cannon Man's total
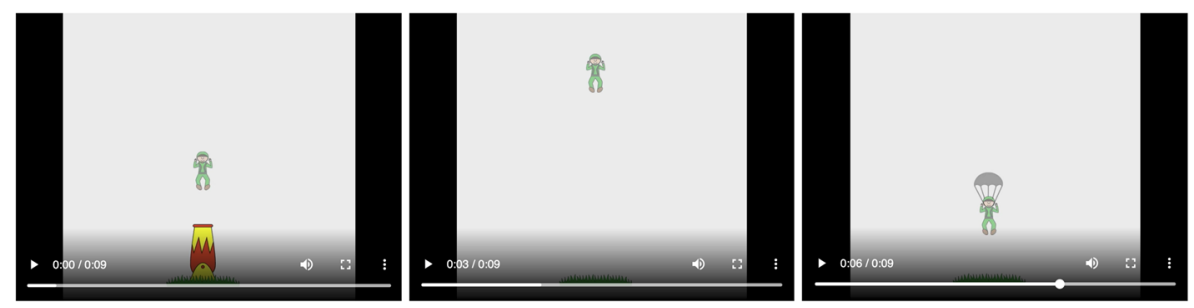

Fig. 2 Still shots of the Cannon Man video animation 
distance, the attribute is a quantity for the student. Employing Thompson's theory, we center students' conceptions of possibilities for measuring attributes, rather than their accuracy in determining measurements.

The theoretical construct of covariational reasoning (Carlson et al. 2002; Thompson and Carlson 2017) builds on Thompson's theory of quantitative reasoning. Through covariational reasoning, students can conceive of relationships among attributes that are capable of varying and being possible to measure. For example, in the Cannon Man situation, students can form or interpret a relationship between two different attributes Cannon Man's height from the ground and Cannon Man's total distance traveled. Students can represent relationships between Cannon Man's height and distance in different ways. We focus on one such representation - a Cartesian graph.

Marton and colleagues (Marton 2014; Kullberg et al. 2017) appeal to discernment and variation to explain the design of student learning opportunities. Design begins with a teacher/researcher identifying an object of learning for students, acknowledging that it is not necessarily available for students to discern, or separate, just because a researcher identifies it. To come to know an object of learning, students discern critical aspects, or dimensions, of it. Researchers can identify some critical aspects prior to an intervention. Yet, critical aspects intertwine with students' perspectives, and different critical aspects may arise for different groups of students (Kullberg et al. 2017). While we have considered some critical aspects (e.g. location of graph attributes on a co-ordinate plane), we acknowledge and welcome the possibility for new critical aspects to emerge.

To open opportunities for student discernment, teacher/researchers design patterns of difference and sameness, first across backgrounds of invariance and then across different backgrounds (Marton 2014). In the design of the patterns, difference precedes sameness (Kullberg et al. 2017; Marton 2014). The patterns take a particular order: contrast, generalization, then fusion. With contrast, designers vary aspects essential to the object of learning; with generalization, designers vary non-essential aspects. With fusion, designers vary both. For example, our intended object of learning is a student conception of a graph as representing a relationship between quantities. Within a single situation (e.g. the Cannon Man), we vary the location of graph attributes, having students sketch two different graphs (contrast). Then, we vary situations (generalization). Across the different situations, we vary both the kinds of graphs and of attributes (fusion).

Researchers' intended objects of learning can differ from students' enacted or lived objects of learning (Kullberg et al. 2017). The former are what teacher/researchers identify that students should learn. Both the enacted and lived objects of learning depend on the teacher/researcher and students' engagement in learning opportunities, and hence may differ from the intended object of learning. While enacted objects of learning refer to spaces of possibilities for student learning, lived objects of learning are what students actually learned. We assume that student conceptions of graphs extend beyond just those conceptions we intend, and that interacting with the same digital tasks can provide different opportunities for different students.

\section{Students' Conceptions of What Graphs Represent}

By the phrase students' conceptions of what graphs represent we mean students' goaldirected mental activity (Simon et al. 2004) related to their graphing. Students can have 
a variety of goals when graphing (e.g. producing an accurate graph, appearing smart in math), and their goals may differ from those of researchers. With the term represent we foreground the perspectives of those engaging in representing (Kaput 1998). If a student is representing with a graph, then that graph represents something for the student. Secondary and university students have wide ranging conceptions of what graphs can represent. We use the term conceptions, rather than a deficit-based term, such as misconceptions. Even if students' conceptions differ from conceptions that researchers intend, they are still conceptions for the student.

When students sketch and interpret graphs, they can conceive graphs iconically, as resembling physical features of observable objects (Clement 1989; Leinhardt et al. 1990). For example, a student may interpret a graph relating attributes of a bottle as resembling the literal shape of a bottle. Johnson (2015) reported the work of a secondary student, Mason, during a task-based, individual interview. He was interpreting a graph representing the height and volume of liquid in a bottle of unknown shape, and initially drew a bottle that resembled the curved shape of the given graph. When Johnson asked him to explain why the bottle would be shaped as he predicted, he began comparing heights and volumes in different sections of the graph, and used those comparisons to explain why the bottle would be shaped differently from the graph. As Mason's work illustrates, opportunities to discern individual attributes represented in a graph can foster students' shifts from physical, feature-based conceptions to relationship-based conceptions.

Students can also conceive of graphs as representing physical features of familiar graphs (Moore and Thompson 2015). For example, students may think that graphs begin in a particular location on the co-ordinate plane, such as the vertical axis. Moore (2016) reported the work of a university student, Belle, working in a digital task environment. Belle stated that she intended to sketch a graph to represent a relationship between attributes. Yet, she anticipated that her graph would start in an unfamiliar location and, hence, she was convinced that her graph could not be accurate. Designing tasks to open opportunities for students to focus on reasoning, rather than accuracy, may foster shifts in student conceptions of graphs.

However, students can also interpret graphs as representing the physical path of an object (Bell and Janvier 1981; Kerslake 1977). For example, consider a situation and a corresponding graph: A child walks from home to school, then back home; a corresponding graph shows the child's distance from school along one axis and the child's total distance traveled along another. A student may conceive of that graph as representing the literal path that the child walked to school. A 'literal motion' interpretation is relevant for student work in digital task environments linking video animations and dynamic graphs. Because the animations are moving, and the graphs are representing attributes of objects shown in the animation, students may think that the graphs should resemble the literal paths of the objects in the animations.

Finally, students can interpret graphs as representing a single attribute varying with elapsing time (Janvier 1998; Johnson and McClintock 2018). For example, consider the co-ordinate plane shown in Fig. 1, representing a toy car's total distance traveled and the toy car's distance from the shrub. A student could think the graph represents the length of a stretchable segment connecting the toy car and the shrub, which varies with elapsing time. Janvier (1998) argued that this 'chronicle' interpretation of graphs, as literal time-passing, contributes to student difficulty with interpreting graphs 
representing non-temporal attributes, such as mass and volume. Despite potential limitations, students who conceive of graphs as representing a single attribute varying as time elapses can shift to conceiving graphs as representing relationships between quantities (Johnson et al. 2017b). A key factor affording students' shifts was their conception of the attributes represented by the graphs, as being capable of varying and being possible to measure. Therefore, it is useful for task designers to provide opportunities for students to conceive of how they could measure the attributes represented in graphs, as well as how those attributes could vary.

\section{A Dual Approach to Digital Task Design}

Tasks encompass more than just observable artifacts; they include the intentions of the task designers, the students working on the task and the teacher/researchers implementing the task (Johnson et al. 2017a). First, we share design elements of our task sequences, then we explain our theoretical and conceptual bases for design. Table 1 provides our blueprint for the task sequences. Each task sequence has six key elements, in which students have opportunities: (1) to conceive of the possibility of measuring attributes given a video animation depicting an object in motion (Task VM); (2) to represent change in individual attributes on a Cartesian plane (Task A1); (3) to sketch a Cartesian graph to represent attributes in the situation (Task G1); (4) to represent change in individual attributes for a new Cartesian plane, with the same attributes represented on different axes (Task A2); (5) to sketch a new Cartesian graph to represent the same attributes (Task G2); (6) to reflect on relationships represented by both graphs (Task R).

We designed the Cannon Man and Toy Car task sequences in Desmos; students moved through a series of screens, which they worked on at their own pace. To

Table 1 Blueprint for the digital task sequences

\section{Task Description}

VM View video animation. Identify measurable attributes. Students view a video animation of a situation depicting an object in motion. They identify attributes in the situation and discuss how it could be possible to measure them.

A1 Represent individual attributes. Students drag dynamic segments along the axes of a Cartesian plane to represent change in individual attributes. Then, students view a computer-generated video of the dynamic segments changing together.

G1 Represent attributes changing together. Students sketch a single Cartesian graph relating both attributes. Then, students view a computer-generated graph and reflect in writing.

A2 Re-represent individual attributes. Students drag dynamic segments along the axes of a new Cartesian plane to represent change in individual attributes. Then, students view a new computer-generated video of the dynamic segments changing together.

G2 Re-represent attributes changing together. Students sketch a new Cartesian graph, with the same attributes represented on different axes. Then, students view a new computer-generated graph and reflect in writing.

$\mathrm{R}$ Reflect on relationships represented by both graphs. Students respond, in writing, to questions focused on relationships represented by the different graphs. 
illustrate, we use the Toy Car digital task sequence. In Screens 1 and 2, students are to view a video and consider the possibility of measuring the attributes in the situation (Task VM). In Screens 3-5 and 9-11, students are to manipulate dynamic segments to represent variation in individual attributes (Tasks A1, A2, respectively; Figs. 3, 4). Then, in Screens 6-7 and 12-13, they are to sketch their own graph, then view a computer-generated graph (Tasks G1, G2, respectively; Figs. 5, 6). In Screens 8 and 14, they then are intended to reflect on what each graph could represent and, in the final screen (Screen 15), are to respond to another student's claim about relationships represented by the graphs (Task R). The Cannon Man task sequence follows the same format as this one.

\section{Promoting Student Conception of Graphs as Representing Relationships between Quantities}

Drawing on Thompson's theory, we designed opportunities for students to conceive of attributes as being possible to measure (Task VM, Table 1). With these opportunities, we mean something other than determining particular amounts of measurement (e.g. the toy car moved three feet). Rather, we mean opportunities for students to explore possibilities for measuring attributes in the situation. For example, students could conceive of the distance between the toy car and a shrub (see Fig. 1) as the length of a stretchable cord, one that changes as the toy car moves along the track.

The types of attributes in digital tasks can impact student opportunities for engaging in covariational reasoning (Johnson et al. 2017b). In our task sequences, the axes represent attributes other than time. One reason for this choice is because students may have yet to conceptualize elapsing time; it just may be something that students feel to be passing as they consider a situation (Thompson, 2012). Even if time is not represented explicitly on a graph axis, it can be an implicit variable. Patterson and McGraw (2018) presented paper and pencil graphing tasks to individual secondary students enrolled in a selective summer mathematics program; they found that an implicit variable of time could influence students' meanings for graphs. In our tasks, time is also an implicit variable. For example, Cannon Man's height and distance change together as time elapses. In the animation, Cannon Man slows down as his

Press play. Move the dynamic segment to show how the toy car's distance from the shrub is changing.
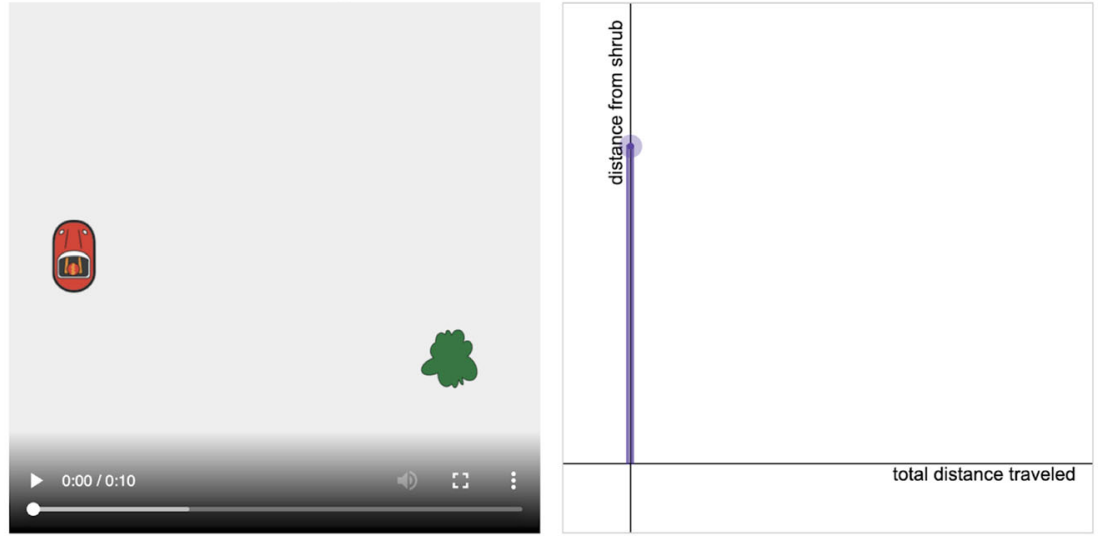

Fig. 3 Toy Car, screen 4: distance from the shrub (vertical) 
Press play. These dynamic segments show how the toy car's distance from the shrub and total distance traveled are changing together.

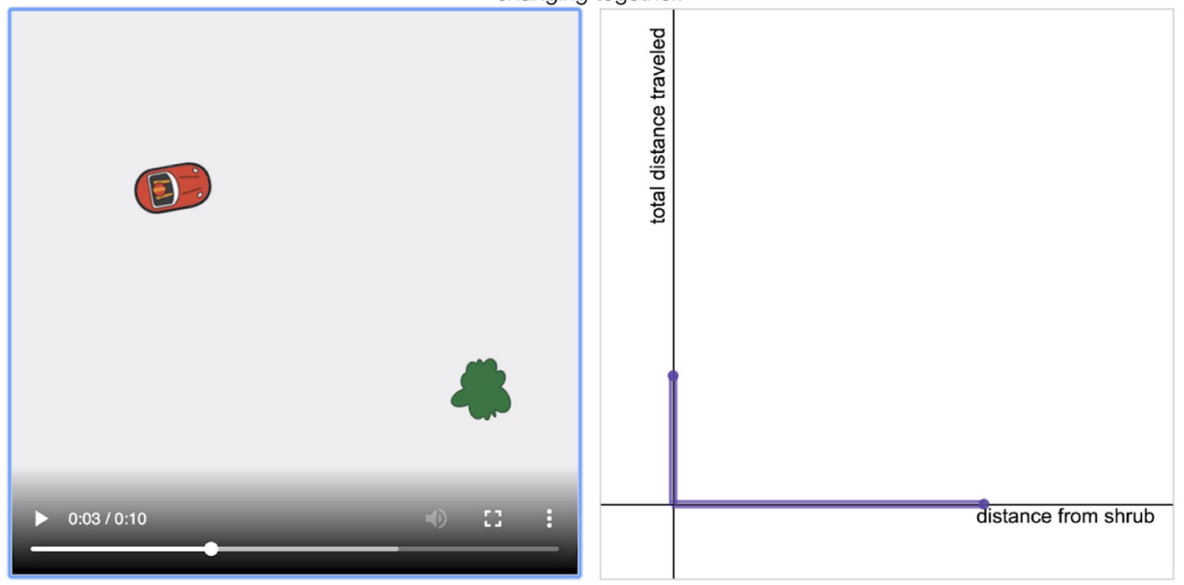

Fig. 4 Toy Car, screen 11: total distance traveled (vertical), distance from the shrub (horizontal)

parachute opens. Yet the computer-generated graphs relating height and distance (Fig. 7) are piecewise-linear. By selecting length attributes, we intend to engineer opportunities for students to distinguish two different elements of attributes: (1) being possible to measure and (2) being capable of varying.

Integrating the theories of Thompson and Marton, we also designed opportunities for students to vary attributes individually, then concurrently (Tasks A1, A2, Table 1). Thompson (2002) advocated that students use their fingers as tools, sliding them along the axes of a graph, to represent change in individual attributes represented by the graph. Hence, we designed dynamic 'stretchy' segments, which students could digitally manipulate to represent variation in individual attributes. Drawing on Marton's theory, we designed patterns of contrast, generalization and fusion.

We provided multiple opportunities for students to vary each attribute, then both attributes, first against a background of invariance (e.g. Tasks A1 and A2 [Table 1] in a

Here is what that graph looks like.
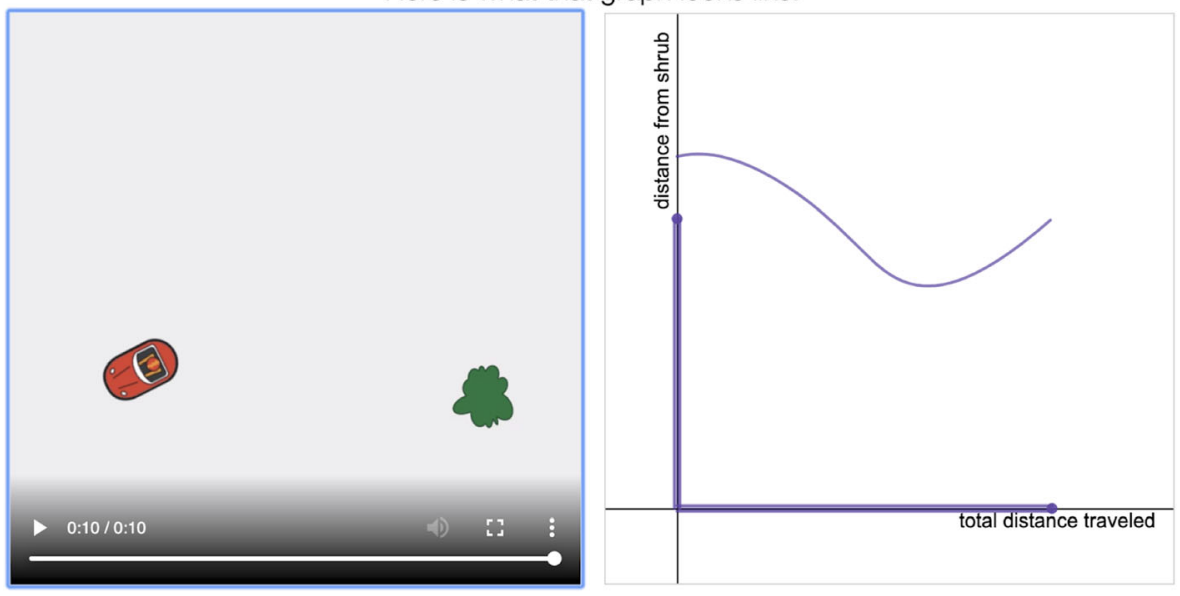

Fig. 5 Toy Car, screen 7: first computer-generated graph 


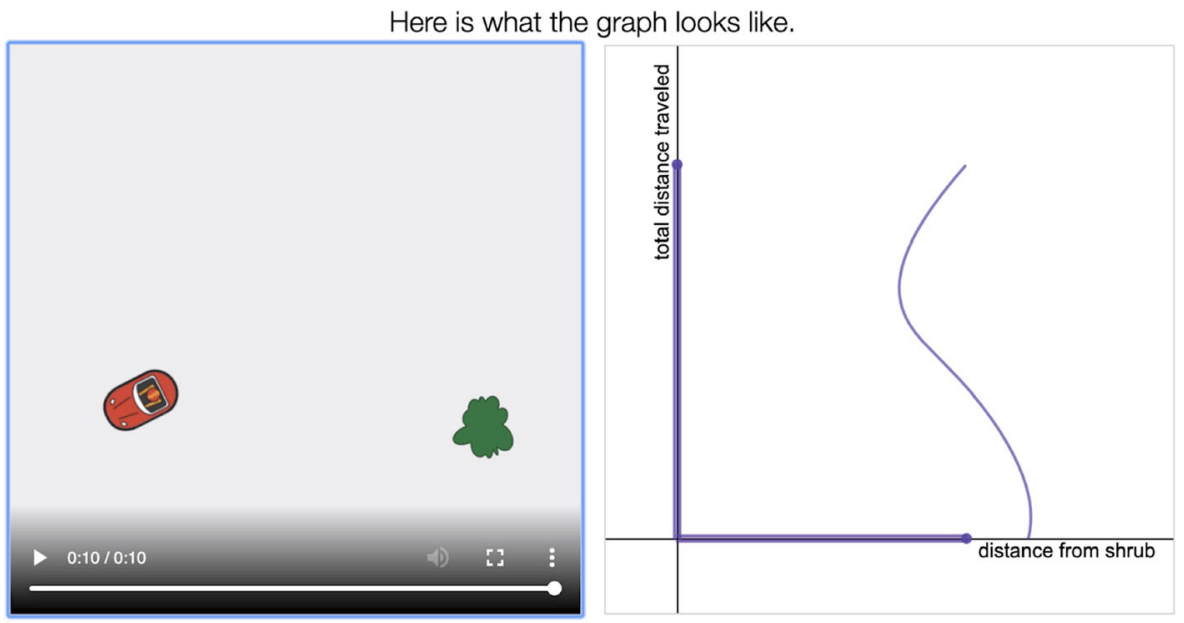

Fig. 6 Toy Car, screen 13: second computer-generated graph

single digital task sequence), and then against different backgrounds (e.g. repeating tasks A1 and A2 [Table 1] across different digital task sequences). For example, Fig. 3 shows the Toy Car's distance from the shrub and total distance traveled represented on the vertical and horizontal axes, respectively, while Fig. 4 switches the representation of the attributes on the axes.

Students have many opportunities to use different types of representations (e.g. tables and graphs) to represent the same relationship between attributes. We took a different approach, designing opportunities for students to use different forms of the same type of representation (e.g. two different-looking graphs) to represent the same relationship between attributes (Tasks G1, G2, Table 1). We drew inspiration for this design choice both from Marton's variation theory and from Moore and colleagues (Moore et al. 2013, 2014). When investigating prospective secondary mathematics teachers' reasoning, Moore and colleagues engaged participants in using different kinds of graphs to represent the same relationship between attributes. Sometimes participants sketched polar and Cartesian graphs (Moore et al. 2013) and, at other times, only different kinds of Cartesian graphs (Moore et al. 2014). Employing Marton's theory, we hypothesized that sketching different graphs representing the same relationships (contrast) could open opportunities for students to discern critical aspects of Cartesian graphs. Figure 7 shows two different graphs representing the same relationship between attributes in the Cannon Man task sequence.
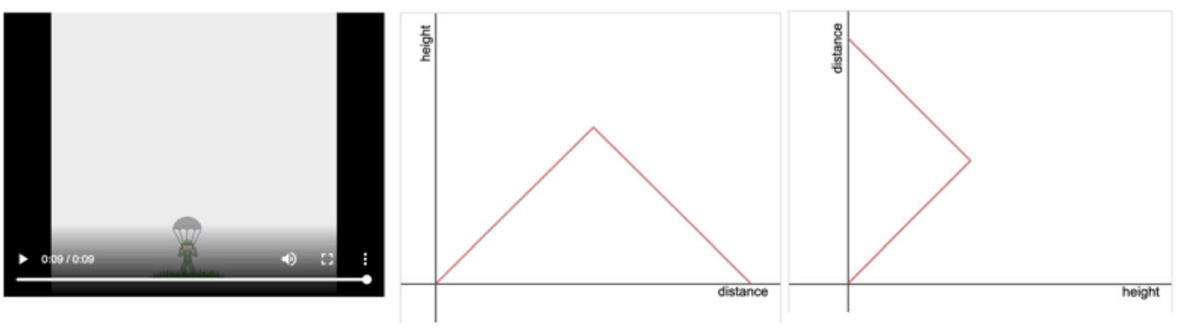

Fig. 7 Two different graphs in the Cannon Man task sequence 


\section{Foregrounding Students' Reasoning and Exploration, Rather than their Accuracy}

While students can sketch graphs accurately, they may not necessarily focus on relationships among attributes. In a study of 325 eighth-grade science students working in a digital task environment, Vitale et al. (2019) investigated how two different approaches might impact students' conceptions of density and buoyancy relationships represented in a mass-volume graph. They found that when students were focused on graphical accuracy, they were less likely to focus on relationships represented by the graph itself. Their findings align with the design of our digital task sequences, which focus on students' reasoning and exploration, rather than on the accuracy of the graphs that students produce.

With each of the tasks in Table 1, we foreground reasoning and exploration, rather than accuracy. In Task VM, students are to reflect on how they might measure attributes in each situation, rather than finding particular measurements. In Tasks A1 and A2, students are to explore change in individual attributes, then interpret how both attributes are changing together. In Tasks G1 and G2, when students are to view the computergenerated graphs, the purpose is not to fix the graphs they have sketched, but rather to make sense of how such a graph could represent a relationship between attributes in a situation. Through the reflection questions (Task R), students are asked to explore similarities and differences between their graphs and the computer-generated graphs.

\section{Methods}

We conducted the study over a four-week time period near the end of the school year (late April through early May) at a suburban high school in the metropolitan area of a large US city, ranked as high performing based on state test results. Prior to asking for student volunteers to participate in the study, over the course of a few months, Johnson met with teachers in the school's mathematics department and visited mathematics classrooms. Through these informal interactions, Johnson intended to communicate that we were not just swooping in to ask some questions, but rather that we were working to get to know their school setting. In this school, students were tracked for mathematics, and we selected students from general track, rather than advanced track courses. They did not receive any special instruction prior to the study. All participants were familiar with Cartesian graphs.

Thirteen students volunteered to participate in the study: Five were in ninth grade ( $\sim 15$ years) and enrolled in an Algebra I course, while the other eight were in eleventh grade ( $\sim 17$ years) and enrolled in an Algebra II course. At the school, $36 \%$ of students qualified for free or reduced lunch (an indicator of low socio-economic status) and 52\% identified as students of color. For their participation, students received a graphing calculator, which they could use for exams and classwork: Many who participated said that they were glad to receive a calculator.

\section{Task-Based Interviews, Exploratory Teaching}

Johnson conducted a series of three task-based interviews (Goldin 2000) with individual students ( $\sim 35 \mathrm{~min}$ per interview, 39 total interviews). Interviews occurred once or 
twice per week, with at least one day between interviews. During the interviews, Johnson engaged in exploratory teaching (Steffe and Thompson 2000) to investigate the viability of the digital tasks for promoting students' conceptions of graphs as representing relationships between quantities. Our focus on reasoning and exploration began with setting the stage for the interview. Johnson told each student that the purpose of the interview was to learn more about students' mathematical reasoning when working on some new digital tasks, that may look different from math tasks they are used to seeing.

Telling students that they were experts in their own reasoning, Johnson explained that her role was to learn from them, asking questions to keep them focused on their reasoning, rather than on the accuracy of their graphs. For example, regardless of the final graph that students created, Johnson asked students to explain what they were trying to graph. If students expressed concern about their graphs being wrong, she told students not to worry about accuracy, emphasizing that the point of these interviews was to learn about their thinking, not to determine whether they were right or wrong. Through these efforts, we intended to make each interview feel more like a conversation, rather than an interrogation of a student by a more knowledgeable other.

During the set of three interviews, students worked on three digital task sequences: The Ferris Wheel, the Cannon Man, and the Toy Car, respectively. In all three interviews, students worked on a digital tablet (an iPad), and Johnson ensured that students progressed through the task sequences in the order intended. In the Ferris Wheel task sequence (first interview), students engaged only in some of the tasks described in Table 1. They worked with an interactive animation of a Ferris wheel, discussed how it could be possible to measure different attributes, then sketched a graph relating those attributes (Tasks VM and G1, Table 1). The second and third interviews (with regard to the Cannon Man and the Toy Car, respectively) incorporated the full task sequence in Table 1.

\section{Data Analysis}

All interviews were video-recorded. During each interview, either McClintock or Gardner wrote field notes. To promote consistency, we used a field note template, which organized the notes based on students' responses to the different tasks in each digital task sequence. Field notes included evidence of students' conceptions of task attributes as possible to measure and capable of varying, as well as evidence of what students may be trying to represent with their graphs.

We focused retrospective analysis on students' responses to the Cartesian graphing tasks (Tasks G1 and G2, see Table 1). Across the set of three interviews, students had opportunities to sketch five Cartesian graphs. Viewing the video recording of each student's work on each of the Cartesian graphing tasks, we engaged in multiple passes of retrospective analysis. First, we described three aspects of students' work: Sketches of (or attempts to sketch) a viable graph; Explanations of their graph (or attempts to explain) in terms of the attributes in the situation; hand movements or other physical motions related to their graphs or task attributes (e.g. using their hands to show how Cannon Man's height changed). Second, we made inferences about students' representing. We used four different codes to characterize students' representing: Covariation (COV), Variation (VAR), Motion (MO), and Iconic (IC). Table 2 provides 
descriptions of each code. With the codes COV and VAR, we draw on Thompson's theory; the codes MO and IC refer to alternative student conceptions of graphs (Bell and Janvier 1981; Kerslake 1977; Moore and Thompson 2015). Across the set of codes, we distinguish between students' conceptions of graphs as representing attribute(s) possible to measure (COV, VAR) or literal objects given in situations (MO, IC). Although we entered our analysis with codes already in mind, we allowed for the possibility for new codes to emerge, or for our existing codes to expand.

Viewing video alphabetically by students' pseudonyms, we completed the first and second passes for each Cartesian graph task in the Ferris wheel and Cannon Man situations. Next, we analyzed the Toy Car situation, which resulted in refinements to our codes. In particular, we expanded the COV code to include students' attempts to represent quantities not explicitly represented in the animation. For example, one student intended to sketch a graph of Cannon Man's height from the ground as it varied with elapsing time, to account for the non-constant rate at which Cannon Man emerged from the Cannon and parachuted to the ground. When we coded a form of representing for a task, a student may have shifted to engaging in that form of representing after an "aha" moment or engaged in that form of representing throughout their work on the task. Although some students demonstrated evidence of more than one form of representing within a task, we elected to use a single code for students' representing within that task. If a student demonstrated partial evidence of one form of representing, but engaged more consistently in another form of representing, we weighed the evidence, then included the code that we interpreted to best characterize the student's representing in that task.

In the third pass of retrospective data analysis, we built from theory to explain students' shifts in representing across the Cartesian graphing tasks in each interview. Drawing on Thompson's theory, we analyzed students' conceptions of attributes in the task as capable of varying and possible to measure. For example, in the Toy Car task sequence, Johnson asked students to explain how they might measure the toy car's distance from the shrub and the toy car's total distance traveled. We built from students' responses to analyze their conceptions of the attributes, as well as their conceptions of relationships between those attributes.

Drawing on Marton's theory, we analyzed spaces of possibilities for student learning, having designed the digital task sequences with this intended object of learning: A

Table 2 Descriptions of codes characterizing students' representing

Code Description of Code

COV Covariation. Students sketched (or attempted to sketch) a graph that depicted a relationship between attributes. Students described the graph in terms of two interrelated attributes.

VAR Variation. Students sketched (or attempted to sketch) two separate graphs, one for each attribute in the situation. Students described each graph in terms of only one attribute (e.g., the "height" graph).

MO Motion. Students sketched (or attempted to sketch) a graph that depicted the motion of an object in a situation (e.g., a toy car moving along a path). Students described the graph in terms of motion.

IC Iconic. Students sketched (or attempted to sketch) a graph that resembled an observable object or familiar graph shape. Students described the graph in terms of its physical characteristics. 
conception of a graph as representing a relationship between quantities. Within each task, we identified student goals for sketching graphs, which we linked to different student conceptions of what graphs could represent. These goals constituted students' enacted objects of learning. Finally, we hypothesized students' lived objects of learning, based on the stability of their conceptions, or shifts in their conceptions, within and across the task sequences.

\section{Results}

We investigated two research questions: (1) How do students conceive of what graphs represent when engaging with digital task sequences? (2) How do students' conceptions of graphs shift when working within and across digital task sequences? We coded four distinct student conceptions of what graphs represented - a relationship between quantities (COV), a single quantity varying with elapsing time (VAR), the literal motion of an object (MO) and an observable object or familiar graph (IC). Table 3 shows the codes for each student, across the digital task sequence.

We found the COV and MO conceptions to be particularly stable. In the Ferris Wheel task sequence, four students demonstrated COV conceptions and four students demonstrated MO conceptions. All eight of them continued to demonstrate either COV or MO conceptions, respectively, during the Cannon Man and Toy Car task sequences.

Overall, four students shifted to COV conceptions. In the Ferris wheel task sequence, two students demonstrated VAR conceptions. Both of them shifted to COV conceptions by the end of the Toy Car task sequence. Students initially demonstrating IC conceptions also shifted conceptions. Two of those three shifted to COV by the end of the Cannon Man task sequence, while the other one shifted to MO.

Table 3 Codes for students' representing, with student's grade level (9th or 11th) in parentheses

\begin{tabular}{|c|c|c|c|c|c|}
\hline $\begin{array}{l}\text { Student(s) } \\
\text { (grade) }\end{array}$ & $\begin{array}{l}\text { Ferris Wheel, G1, } \\
\text { Interview } 1\end{array}$ & $\begin{array}{l}\text { Cannon Man, G1, } \\
\text { Interview } 2\end{array}$ & $\begin{array}{l}\text { Cannon Man, G2, } \\
\text { Interview } 2\end{array}$ & $\begin{array}{l}\text { Toy Car, G1, } \\
\text { Interview } 3\end{array}$ & $\begin{array}{l}\text { Toy Car, G2, } \\
\text { Interview } 3\end{array}$ \\
\hline $\begin{array}{l}\text { Alex (11th), } \\
\text { Austin (9th), } \\
\text { Jayden } \\
\text { (11th), Tyler } \\
\text { (9th) }\end{array}$ & $\mathrm{COV}$ & $\mathrm{COV}$ & $\mathrm{COV}$ & $\mathrm{COV}$ & $\mathrm{COV}$ \\
\hline Harun (11th) & VAR & $\mathrm{COV}$ & $\mathrm{COV}$ & $\mathrm{COV}$ & $\mathrm{COV}$ \\
\hline Aisha (9th) & VAR & VAR & $\mathrm{COV}$ & VAR & $\mathrm{COV}$ \\
\hline Amanda (11th) & IC & $\mathrm{COV}$ & $\mathrm{COV}$ & $\mathrm{COV}$ & $\mathrm{COV}$ \\
\hline David (11th) & IC & $\mathrm{MO}$ & $\mathrm{COV}$ & $\mathrm{COV}$ & $\mathrm{COV}$ \\
\hline Kara (11th) & $\mathrm{MO}$ & $\mathrm{MO}$ & $\mathrm{COV}$ & $\mathrm{MO}$ & $\mathrm{MO}$ \\
\hline $\begin{array}{l}\text { Keshia (9th), } \\
\text { Carmen } \\
\text { (11th) }\end{array}$ & $\mathrm{MO}$ & $\mathrm{MO}$ & VAR & $\mathrm{MO}$ & $\mathrm{MO}$ \\
\hline Gemma (9th) & $\mathrm{MO}$ & $\mathrm{MO}$ & MO & $\mathrm{MO}$ & $\mathrm{MO}$ \\
\hline Eliza (11th) & IC & $\mathrm{MO}$ & $\mathrm{MO}$ & $\mathrm{MO}$ & $\mathrm{MO}$ \\
\hline
\end{tabular}




\section{How Students Conceived of What Graphs Represent}

We identified three goals, aligned with different conceptions: How do I show what I see? (IC/MO); How many graphs do I need? (VAR); What are the things I am graphing? (COV). Although we coded for IC/MO separately, we found students' goals to be compatible - to attempt to sketch a graph to show what they literally saw in a video animation. During interviews, students with VAR conceptions often asked if they should draw one graph or two, and Johnson would tell them to use however many graphs they would like. In contrast, students with COV conceptions wondered about which attributes they were graphing, and they frequently looked at the axes when deciding how to sketch their graphs. Employing Marton's theory, we interpret each of these three goals to be enacted objects of learning. Overall, only two of the goals became lived objects of learning: the IC/MO goal, How do I show what I see? (five students) and the COV goal, What things am I graphing? (eight students). We report on five students: David, Carmen, Keshia, Aisha and Alex. These five students were representative of the range of stability or shifts in conceptions of all thirteen students in the study.

When students conceived of graphs as representing observable features or motion of objects, their goal was to sketch a graph that showed what they saw (IC/MO). Prior to sketching the graph shown in Fig. 8, right, Johnson asked David to explain how he might measure the distance traveled and height from the ground for a cart beginning at the base, then moving counterclockwise around one revolution of a Ferris wheel (Fig. 8, left). David attempted to determine particular amounts of height and distance, stating, "I think of how much the distance would be, in pi. I think it would be three-fourths pi." Going further, he said, "You can think about the circle [the Ferris wheel, Fig. 8, left] as a grid. I would think about the center as being zero, zero, and maybe here [pointing to the lower right] being three, negative three."

Based on Thompson's theory, we interpret David to be conceiving of distance and height as amounts to find rather than attributes possible to measure (quantities). When requested to sketch a graph relating the Ferris wheel cart's distance traveled and height from the ground for one revolution of the wheel, David asked, "Would you like me to
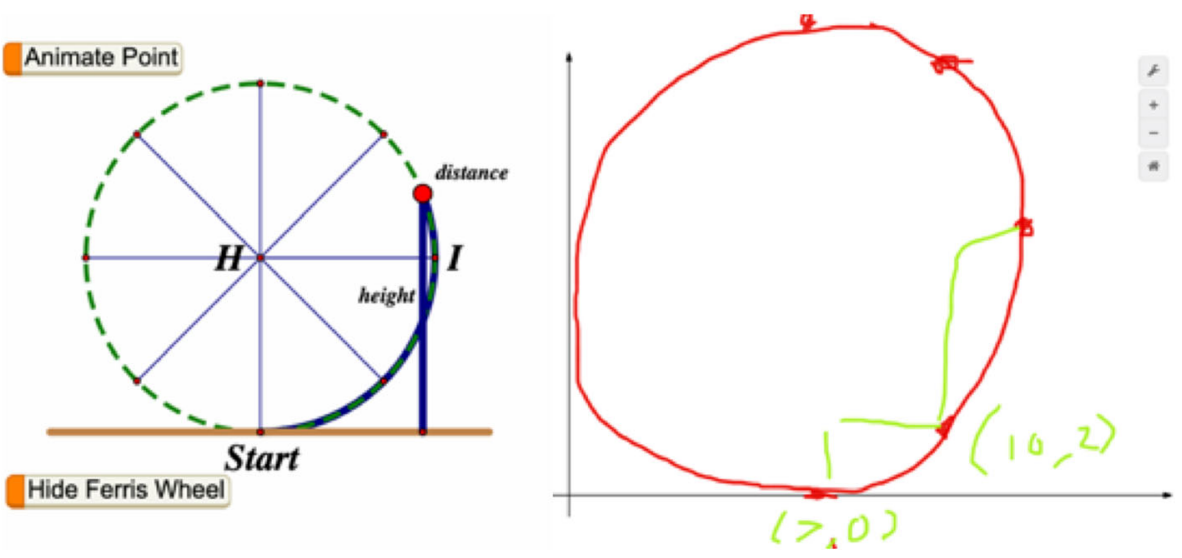

Fig. 8 Ferris Wheel interactive animation (left), David's graph (right) 
imagine an equation for that?" Johnson told him he could do whatever he liked and David then produced the graph shown in Fig. 8 (right). We coded his conception IC, because his graph resembled the image of the Ferris wheel that he had seen in the interactive animation. His co-ordinates represented different places on the wheel, based on approximate locations from the origin (Fig. 8, right). Employing Marton's theory, we interpret David's enacted object of learning to be that, when there is no equation given, a graph shows what he saw in the situation.

Students may conceive of attributes in ways consistent with Thompson's perspective on quantities, but still hold MO conceptions of graphs. In the Toy Car G1 task, Carmen demonstrated that she conceived both of the car's total distance traveled and of the distance from the shrub as capable of varying and possible to measure (quantities, per Thompson's theory). Yet, she sketched a graph representing the path of the toy car (Fig. 9), circling its beginning and ending points, and including a dot to represent the shrub (Fig. 9, right). Carmen explained her graph this way: "What I thought about was that, like, it's a starting point. And it's starting to go closer and then it starts going back further. So that's how I saw it. I saw it as if it's going closer, then further." Not only did her graph bear resemblance to the path of the toy car, she explained her graph in terms of the motion of the toy car; hence we coded Carmen's conception as MO. Employing Marton's theory, we interpret her enacted object of learning to be that a graph literally shows the motion of an object in an animation.

Students who demonstrate MO conceptions may sketch graphs bearing less-striking resemblances to objects' literal motion. To illustrate this, we share Keshia's work on the Toy Car G1 task. Like Carmen, prior to sketching a graph, Keshia demonstrated that she conceived of the toy car's distance from the shrub and distance traveled as quantities, as per Thompson's theory. After watching the Toy Car video, Keshia explained that she thought she could measure the toy car's distance traveled. When

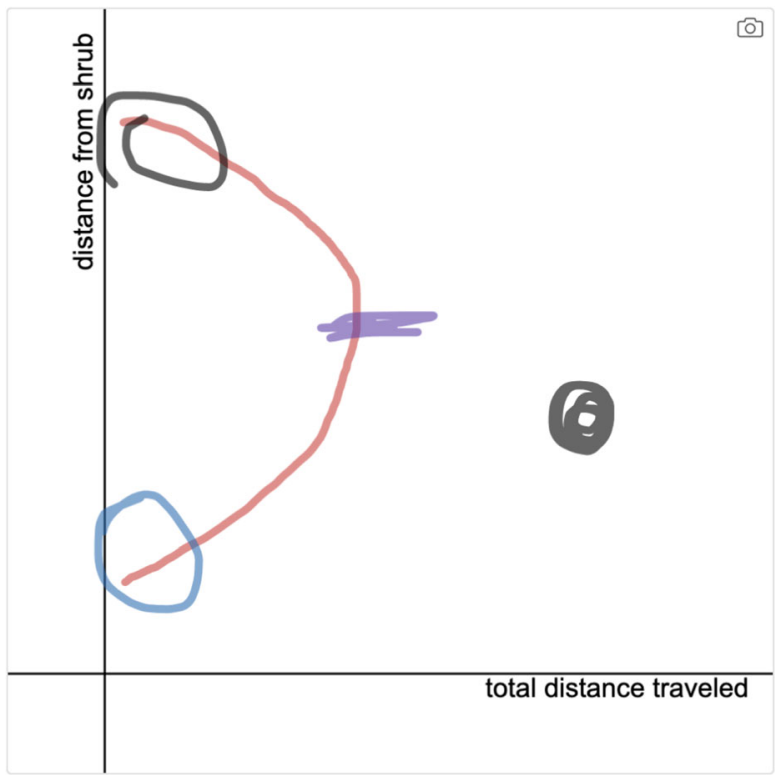

Fig. 9 Carmen's graph for the Toy Car G1 task 
Keshia read that the distance from the shrub could be another attribute to measure, she stated that she had not thought about that possibility, but it was a "good one". While explaining, Keshia moved her hand back and forth from the car to the shrub, then sketched the graph shown in Fig. 10. She explained her graph in terms both of distance and of movement: "It's showing you how far it went all together [moves her hand along the graph, going from left to right], and it's also showing you when it starts moving up, and when the slope starts moving down". Because Keshia moved her hand along the graph when talking about the distance as well as focusing on the movement of the toy car and graph, we coded her conception as MO.

While Keshia's MO conception accounted for much of her work in the digital task sequences, we determined an additional critical aspect (Marton 2014) - her notion of what graphs should represent. To illustrate, when Keshia was sketching the graph shown in Fig. 10, she said, "Maybe it would look right if it's a squiggly line, but that doesn't seem normal in a graph". Although Keshia entertained the possibility of a nonlinear graph, she discounted it, based on what she deemed graphs should be like. Hence, employing Marton's theory, we interpret Keshia's enacted object of learning to be that a graph should not only represent the motion of an object in an animation, but also fit in with her notions of what a graph should be.

When students conceived of graphs as representing a single quantity varying with elapsing time, their goal was to determine how many graphs they needed (VAR). For the Cannon Man G1 task, Aisha immediately asked, "Can it be two different lines?", and Johnson confirmed that that would be okay. Aisha then sketched the graphs shown in Fig. 11, saying, "This would be distance [sketching the linear portion, then pointing to the distance axis], and then it would be a parabola for the height [sketching the curved portion, then pointing to the height axis]". Like Keshia and Carmen, prior to her work on the Cannon Man G1 task, Aisha demonstrated that she conceived of Cannon

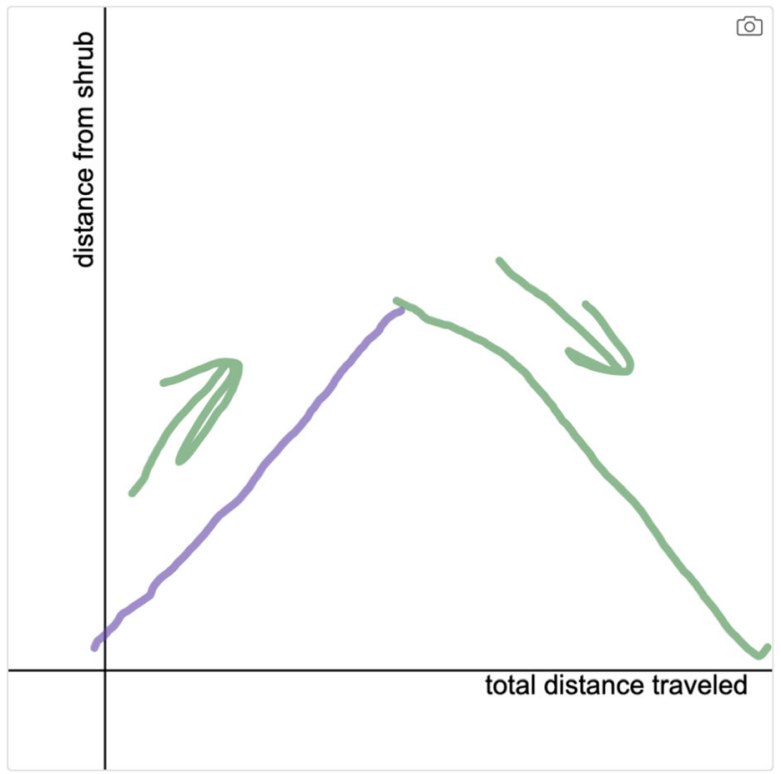

Fig. 10 Keshia's graph for the Toy Car G1 task 
Man's height from the ground and total distance traveled as capable of varying and possible to measure (quantities, as per Thompson's theory). Aisha added points to the height graph, explaining that each point represented a different height for Cannon Man.

Aisha also drew connections between her distance graph and the continually increasing dynamic segment she observed moving along the distance axis in Cannon Man Task A1, stating: "If this keeps going [moving her hand along the distance axis], might as well make it a linear". Because she demonstrated that each of her graphs represented a single quantity, varying with elapsing time, we coded Aisha's conception as VAR. Employing Marton's theory, we interpret Aisha's enacted object of learning to be that graphs represent individual quantities varying with elapsing time. Aisha's conception shifted during the Cannon Man task sequence, and we share more about that shift in the next sub-section.

When students conceived of graphs as representing relationships between quantities, their goal was to sketch a graph that showed both attributes simultaneously (COV). Alex demonstrated that he conceived of Cannon Man's height from the ground and total distance traveled as capable of varying and possible to measure (quantities, as per Thompson's theory). For the Cannon Man G2 task, Alex reflected on how each of the quantities were varying when he worked to sketch the graph shown in Fig. 12: "Height's going to go back down at some point. Distance is always going to be increasing. I have to figure out a way to draw these together." Alex drew arrows to the bottom and left of the horizontal and vertical axes, respectively, to show how Cannon Man's height and distance were varying. Although Alex and Keshia both drew arrows in their graphs, Alex's arrows represented the variation in each of the attributes and separated the variation from the shape of the graph itself. Because he worked to sketch a graph to relate both attributes, we coded Alex's conception as COV.

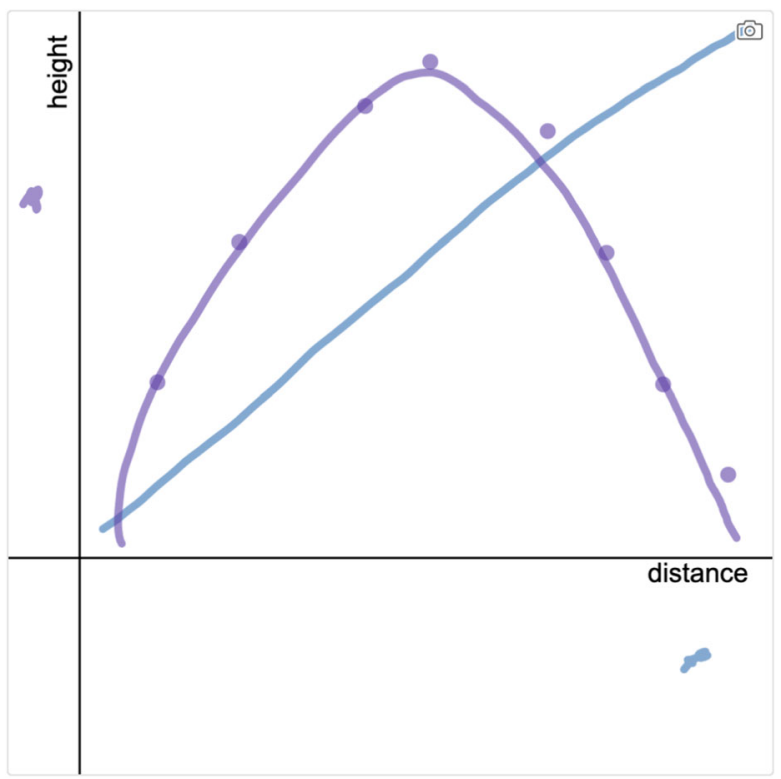

Fig. 11 Aisha's graphs for the Cannon Man G1 task 
Similar to Keshia, Alex's notion of what graphs should represent impacted his work on the digital task sequences. He questioned the viability of his graph shown in Fig. 12, commenting: "Usually most graphs are going that way [pointing to the right]. They're not going back that way [pointing to the left]. I've never seen a graph go like that [pointing to the left]. It just doesn't match up." While Alex drew an accurate graph, he was not convinced his graph could make sense, based on what he deemed graphs should do. Employing Marton's theory, we interpret Alex's enacted object of learning to be that a graph should not only represent relationships between quantities, but also fit in with his notions of what a graph should be. Alex and Keshia both demonstrated the compelling nature of students' notions of what graphs should be and how those notions can impact students' work in digital task sequences.

\section{How Students' Conceptions of Graphs Shifted when Working within and across Digital Task Sequences}

We focus our analysis on shifts that occurred across different tasks within the same digital task sequence, during the same interview. Mostly, we saw shifts in students' conceptions during the Cannon Man task sequence. Only one student (Aisha) demonstrated a shift in her conception of graphs during the Toy Car task sequence - and that shift was the same as what she demonstrated in the Cannon Man task sequence. We report on two students, Aisha and David, who represent the breadth of shifts that we saw across all students.

In the Cannon Man digital task sequence, Aisha shifted from conceiving of two quantities varying individually with elapsing time to conceiving of a relationship between quantities (from VAR to COV). For the Cannon Man G2 task, Aisha no longer asked if she could draw two different graphs. Rather, she drew one graph

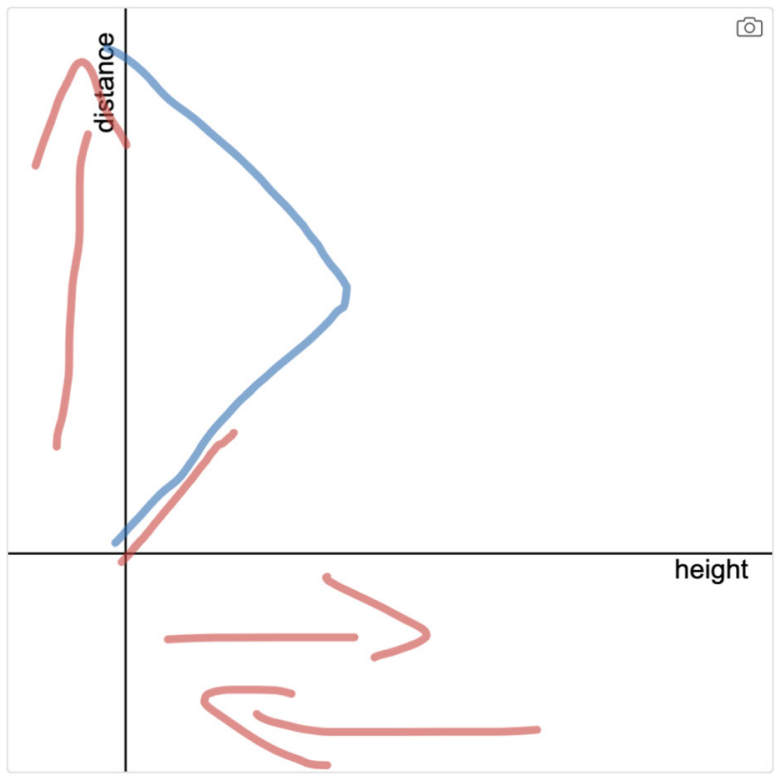

Fig. 12 Alex's graph for the Cannon Man G2 task 
(Fig. 13), with two related parts: A line segment, extending along the vertical axis, and a graph she called a 'parabola', opening to the left, with end-points on the vertical axis. We view Aisha's shift in her goal as an indication of a shift in her conception of what is possible for graphs to represent.

As with Alex and Keshia, Aisha's notions of what graphs should represent impacted her work in the digital task sequence. When she began to sketch a graph with distance and height represented on the vertical and horizontal axes, respectively, she said, "Usually, if you give somebody a graph, it's facing this way, yes. But I imagine the distance on the ground [rotating iPad $90^{\circ}$ counterclockwise so the distance axis appears horizontal], which I can't do." In her response, Aisha distinguished between how she conceived of distance (on the ground) and how the graph represented distance along the vertical axis. Rather than just sketching a graph, Aisha explained what she 'wanted' a graph to do. To encourage her, Johnson said, "Even if it doesn't look like how you are used to graphs looking, draw it like how you want it to go and tell me why". In response, Aisha sketched the graph shown in Fig. 13, explaining how her graph showed Cannon Man's height increasing and decreasing (arrows along the graph), and Cannon Man's total distance continuing to increase (arrows along the vertical axis).

Employing Thompson's theory, we interpret that Aisha was beginning to demonstrate evidence of a COV conception of graphs. The vertical segment representing the changing distance was an important part of her graph. When she saw the computergenerated graph (Fig. 7, right), she said that she expected to see that segment. We claim that Aisha shifted from VAR to COV because her goal shifted from sketching two separate graphs to sketching interrelated representations (a distance segment and a height graph), to account for the direction of change in each attribute. Notably, her graph was sufficient for her, despite her discerning differences between the computer-

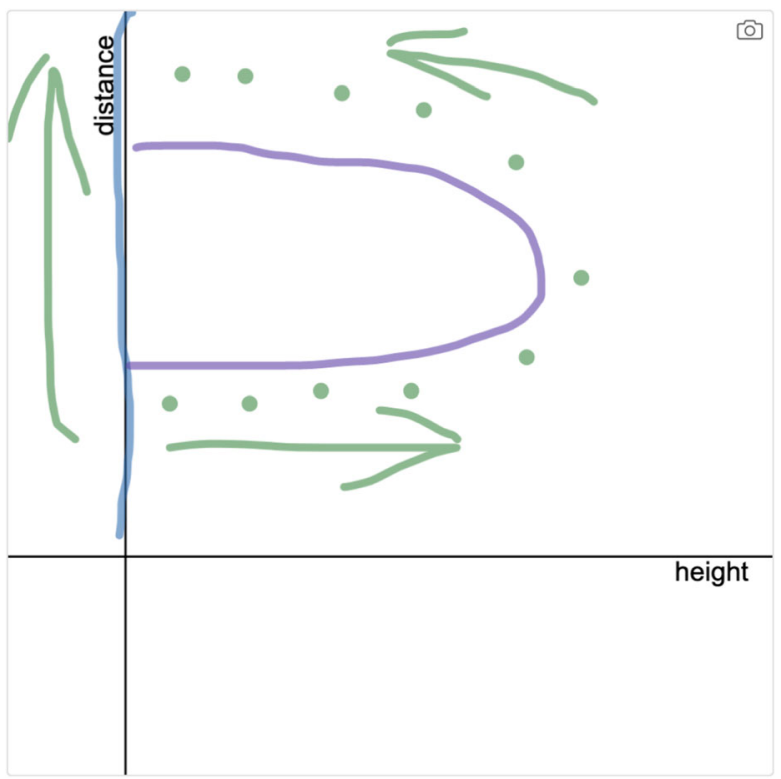

Fig. 13 Aisha's graph for the Cannon Man G2 task 
generated graph and her graph: "It's the same thing to me, essentially. It's just straight and not curved."

Employing Marton's theory, we interpret Aisha's enacted object of learning to have shifted during the Cannon Man digital task sequence. In the specific G2 task, Aisha conceived of graphs as representing relationships between attributes, even when those attributes are depicted in unfamiliar ways. In the Toy Car task sequence, Aisha again shifted from VAR to COV, just as she had done in the Cannon Man task sequence. While working on the Cannon Man task sequence was sufficient to shift some students' conceptions for the remainder of the digital task sequences (e.g. Harun, David, Amanda, see Table 3), she demonstrated the same shift in a new task sequence. Because she continued to shift from VAR to COV, we interpret Aisha's lived object of learning to be the same as her enacted object of learning in the Cannon Man G2 task. Opportunities to work on similar digital task sequences having different backgrounds could promote stability in her shifts to COV.

In the Cannon Man digital task sequence, David shifted his conceptions of what graphs represent, from the Cannon Man G1 task (MO) to the Cannon Man G2 task (COV). Like his goal for the Ferris Wheel task sequence, David's goal on the Cannon Man G1 task was to represent what he saw. He demonstrated evidence that he conceived of the graph as representing the literal motion of Cannon Man. In the Cannon Man G2 task, he shifted his conception, to account for Cannon Man's height and distance in his graph. Figure 14 shows his graphs for the Cannon Man G1 and G2 tasks, respectively.

Prior to sketching the graph shown in Fig. 14 (left), David manipulated the dynamic segments to represent changes in Cannon Man's height and distance (Cannon Man task A1). In the transcript that follows, Johnson asked him to explain why he thought manipulating the segments was more challenging than sketching a graph.

Researcher: What makes it hard?

David: When you see something in real life, something like this. You're not seeing just distance or just height. You're seeing the actual graph, if that makes

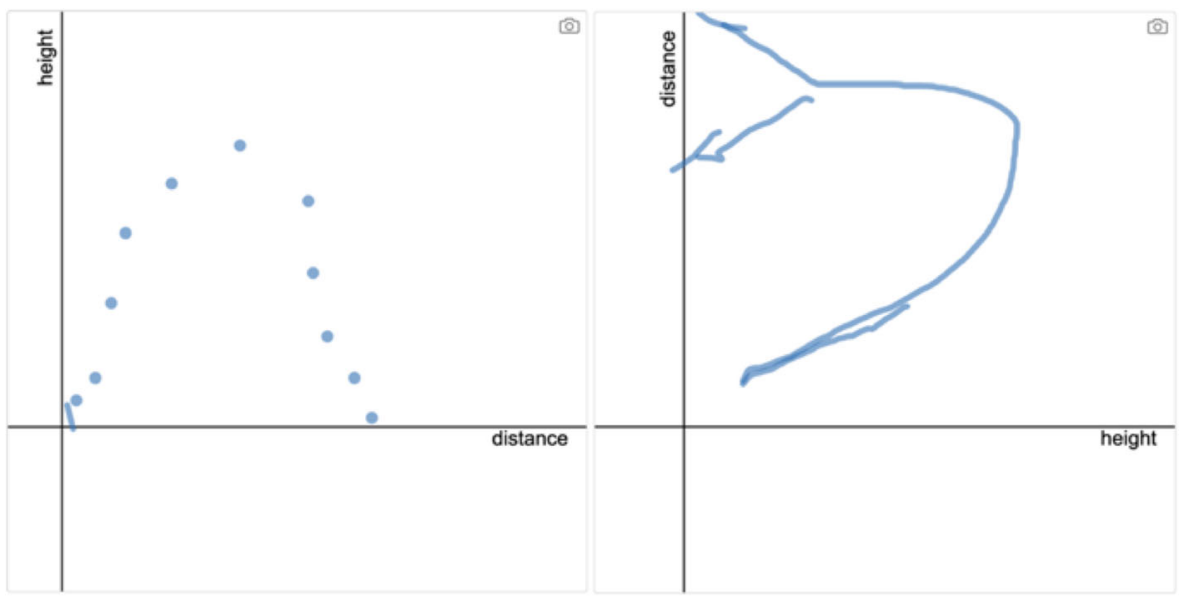

Fig. 14 David's graphs for the Cannon Man graphing tasks - G1 (left) and G2 (right) 
sense. I think it's easier to understand when you have the option to do that instead of just distance, or just height.

R: When you are seeing the actual graph, what does the actual graph show you?

D: Shows me more closely the path he's taking. With just height and distance, you only see, just how high he's going or how far out he's going, but you don't actually see the true line or path he's following.

Manipulating the dynamic segments provided David with an opportunity to conceive individual attributes of height and distance as capable of varying and possible to measure (quantities, as per Thompson's theory). He contrasted these segments with what he termed an 'actual' graph, which would show Cannon Man's literal path. When he sketched the graph shown in Fig. 14 (left), he asked if he could use points, to which Johnson said he could do whatever he preferred. He started by plotting the maximum point, because "it makes the graph easier to find a path for".

David explained his graph in terms of the path that Cannon Man traveled: "Here's where he starts, maybe two or three feet above, just cause he's in the cannon, then he follows this path until he reaches the max, comes back down and goes completely to the ground". In this Cannon Man G1 task, we coded his conception as MO, because he sketched a graph to represent the literal path of Cannon Man. Employing Marton's theory, we interpret his enacted object of learning to be that graphs represent the actual motion of objects.

As with Aisha, David's notion of what a graph should represent impacted his work on the task. Prior to sketching the graph shown in Fig. 14 (right), he expressed that he thought it would be "kind of hard", and then asked Johnson, "Do you want me to draw what I think?" She confirmed this and he immediately began sketching the graph shown in Fig. 14 (right), starting near the origin, then moving along the graph, adding the detached blue segment in the upper corner after he sketched the rest of the graph. We interpret his question to refer, in part, to whether he should attempt to show realistic aspects when sketching a graph, which he thought was important to do. He did represent realistic aspects by adding the detached blue segment in the upper part of the graph. From our perspective, because he included an additional segment, his graph represents a space of possibilities for a graph of Cannon Man, rather than a single graph. Although aspects of his graph still represented the motion of Cannon Man, we interpret David's goal to have shifted from solely showing the path of Cannon Man, to accounting for Cannon Man's height and distance. Therefore, we claim that his conception shifted from MO to COV, albeit an inchoate form of COV.

Employing Thompson's theory, David conceived of Cannon Man's total distance traveled as something different from the distance we intended when designing this task. We intended the total distance traveled to be the vertical distance, both up and down. In contrast, he described Cannon Man actually moving from left to right, despite the video showing only up and down movement. He conceived of the distance as the horizontal distance traveled along the ground, when Cannon Man moved from left to right, and he explained that this distance could be different depending on how the parachute opened. David did, however, conceive of the height in a way consistent with our task design, as measuring Cannon Man's vertical distance from the ground. He readily manipulated a dynamic segment on the horizontal axis to represent Cannon Man's height, accounting 
for the varying speed at which he traveled as he moved the segment. When sketching the graph shown in Fig. 14 (right), David began the graph above the origin to account for Cannon Man's height from the ground, which would not actually be zero.

Employing Marton's theory, we interpret David's enacted object of learning in the Cannon Man task sequence to be that graphs account for given attributes in a situation, yet still somehow show the literal path of an object. Given his interpretation of distance, it was difficult to separate the actual path of Cannon Man from the shape of the graph itself, even though the graph for this G2 task represented the distance along the vertical axis, rather than along the horizontal one. Therefore, while we coded David's conception as COV, we gathered additional evidence from the Toy Car task sequence to make claims about his lived object of learning. During the Toy Car task sequence, he sketched graphs that represented a relationship between the toy car's distance from the shrub and the toy car's total distance traveled.

We claim that David's lived object of learning was that graphs represent a coordination between different amounts of quantities. To illustrate, we explain how he conceived of his graph (Fig. 15) for the final graphing task, Toy Car G2. He chose to plot individual points, because he thought he could be more accurate, describing how he thought about the dynamic segments when deciding where to plot different points. Johnson asked him to illustrate for a specific point, and he drew segments along the horizontal and vertical axes, stating: "For the short distance he's traveled so far [pointing to segment on the vertical axis], that's how far he is out from the bush [pointing to segment on the horizontal axis]". Employing Thompson's theory, we interpret that David conceived of each point as representing a co-ordination between amounts of different distances; or, to use Thompson's term, he conceived of each point as a multiplicative object.

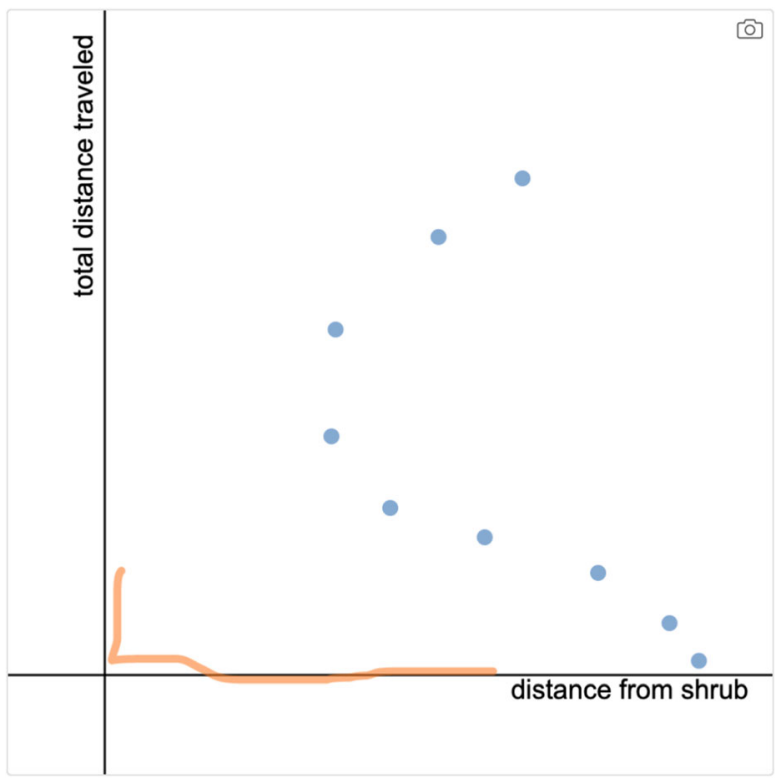

Fig. 15 David's graph for the Toy Car G2 task 
Across all students, David's shift was the most drastic. Notably, he was the only student who, after demonstrating a MO conception, went on to demonstrate a COV conception as a lived object of learning. Opportunities to manipulate the dynamic segments, representing each attribute, fostered his conception of a graph as representing a relationship between quantities. We posit that the change in the type of motion from the Cannon Man to the Toy Car opened more possibilities for David's emerging COV conception to become more stable.

\section{Discussion}

We identified students' goals for their graphing, aligned to their conceptions of graphs. Students demonstrating IC or MO conceptions had a goal of using their graphs to show what they literally saw in an animation. Students demonstrating VAR conceptions had a goal of using a graph to represent individual attributes. Students demonstrating COV conceptions had a goal of co-ordinating different attributes in a single graph. In addition, a fourth student goal emerged through our analysis: What graphs should represent. We found this last goal to be compelling for students demonstrating a range of conceptions, because it could afford or constrain their other goals for graphing. Hence, we recommend that researchers design learning experiences to account for students' notions of what graphs should represent. In our design, we aimed to communicate to students that we cared about their reasoning more than their answers, and we view that design choice as opening possibilities for students to make their notions explicit.

Our research questions focused on students' conceptions of what graphs represented and Thompson's theory was central to our analysis of them. Students who demonstrated a COV conception conceived of graph attributes as quantities. However, conceiving of graph attributes as quantities was not sufficient for students to demonstrate COV conceptions of graphs (see our analysis of Carmen). Researchers also may employ Thompson's theory to examine students' conceptions of mathematical objects represented in graphs, such as slope. For instance, Ellis et al. (2018) drew connections between two middle-school students' quantitative reasoning and their conceptions of what slope could represent. In our analysis, we characterized students as having COV conceptions of graphs, but we did not engage in analysis to distinguish gradations in students' COV conceptions. In future research, scholars could work from the levels of variational and covariational reasoning posited by Thompson and Carlson (2017) to engage in more fine-grained analysis both of students' VAR and of their COV conceptions of graphs.

\section{Shifts in Students' Conceptions of Graphs}

We saw a variety of pathways in students' shifts to covariational reasoning within and across the digital task sequences (see Table 3). While we analyzed four distinct conceptions of graphs (IC, MO, VAR, COV), students did not necessarily need to progress through all four conceptions to shift to a COV conception. Most students' shifts in the Cannon Man task sequence lasted across the Toy Car task sequence; however, some students' shifts were fleeting or fluid. In the Cannon Man task 
sequence, three students (Kara, Keshia and Carmen; see Table 3) demonstrated fleeting shifts from MO conceptions of graphs to VAR or COV conceptions, but they continued to demonstrate MO conceptions in the Toy Car task sequence. In contrast, Aisha demonstrated a more fluid shift to a COV conception of graphs, as she re-progressed in her shift from a VAR conception to a COV conception in the Toy Car task sequence.

When students demonstrated VAR conceptions of graphs, we were successful in providing opportunities for them to shift to COV conceptions. However, when students demonstrated MO conceptions, we were less successful. Although six students demonstrated MO conceptions of graphs, only one student (David) demonstrated a COV conception as a lived object of learning. Rather than characterizing our student participants as having deficits that mitigated their shifts, we intentionally characterize our efforts to engineer learning opportunities as being more or less successful. With this decision, we intend to convey that, under different circumstances or with different task sequences, these same students might have shifted to COV conceptions of graphs, despite not demonstrating such shifts during this study. A variation theory lens helped us to guard against a deficit perspective, because we were constantly weighing what we intended for students to learn, the opportunities we created for students to learn and what students actually learned during their work with the digital task sequences.

When students demonstrated or shifted to MO conceptions of graphs, their conceptions remained particularly stable throughout the task sequences. Students may have encountered many graphs that share observable characteristics with the motion of physical objects, even though graphs do not need to share such characteristics. Students demonstrating MO conceptions could benefit from embodied tasks for graphing motion (Duijzer et al. 2019), so that they could have opportunities to form links between their own movements and the appearance of graphs they sketch. Task sequences could begin with a background of invariance, and different kinds of motion, and then incorporate variation in both backgrounds and motion.

With different methodological choices or different theoretical lenses, researchers could expand possibilities for studying students' graphing activity. When we examined shifts in students' conceptions of graphs, we selected a single code (e.g. VAR) to characterize their overall representing on a single task (e.g. Cannon Man G2). To study finer-grained shifts, researchers could investigate students' micro-shifts, within a single task. Such investigations could draw on single, illustrative cases to explain why certain conceptions (e.g. MO) remain so persistent. While we chose to integrate Thompson's theory of quantitative reasoning and Marton's variation theory, scholars could employ different theoretical lenses to investigate students' work with digital task sequences such as the ones we described.

\section{Conclusion}

In our digital task design, we had a dual aim: To promote students' conceptions of graphs as representing relationships between quantities (COV) and to open opportunities for students to focus on reasoning and exploration, rather than accuracy. While students may hold many conceptions of graphs, a COV conception is important for students to develop. First, it can support students' interpretation of graphs containing non-temporal attributes, such as the mass-volume graphs reported on by Vitale et al. 
(2019). Second, students demonstrating a COV conception are well positioned to analyze critically information presented in graphs, because they have a goal of coordinating attributes represented on different axes.

We contend that opportunities for students' reasoning and exploration encompass not only the digital task sequences themselves, but also the interactions that students have during their work on those task sequences. We anticipated that student participants may have perceived a need to perform, which is why, throughout the interviews, Johnson consistently communicated that we cared more about student reasoning than we did about their graphical accuracy. We find it impossible to disentangle our efforts to promote students' conceptions of graphs and to open students' opportunities for reasoning. Through our synergistic efforts, we engendered students' shifts to relationship-based conceptions of graphs.

As researchers investigating students' conceptions, our design decisions are never neutral. To guard against deficit perspectives, researchers investigating students' mathematical conceptions should interrogate their own research designs, so that they may uncover potential biases. By critiquing their own research designs, rather than pointing to deficits in their student participants, researchers can promote students as capable of engaging in rich mathematical thinking and reasoning, even if students have yet to demonstrate such reasoning in a research setting.

Acknowledgments The development of the digital task sequences was supported by a U.S. National Science Foundation Grant (DUE-1709903). This study was supported by a Faculty Development Grant from the University of Colorado Denver. Opinions, findings and conclusions are those of the authors. We thank Dan Meyer for his support of the development of the digital task sequences in Desmos.

Open Access This article is licensed under a Creative Commons Attribution 4.0 International License, which permits use, sharing, adaptation, distribution and reproduction in any medium or format, as long as you give appropriate credit to the original author(s) and the source, provide a link to the Creative Commons licence, and indicate if changes were made. The images or other third party material in this article are included in the article's Creative Commons licence, unless indicated otherwise in a credit line to the material. If material is not included in the article's Creative Commons licence and your intended use is not permitted by statutory regulation or exceeds the permitted use, you will need to obtain permission directly from the copyright holder. To view a copy of this licence, visit http://creativecommons.org/licenses/by/4.0/.

\section{References}

Bell, A., \& Janvier, C. (1981). The interpretation of graphs representing situations. For the Learning of Mathematics, 2(1), $34-42$.

Carlson, M., Jacobs, S., Coe, E., Larsen, S., \& Hsu, E. (2002). Applying covariational reasoning while modeling dynamic events: A framework and a study. Journal for Research in Mathematics Education, 33(5), 352-378.

Clement, J. (1989). The concept of variation and misconceptions in Cartesian graphing. Focus on Learning Problems in Mathematics, 11(1/2), 77-87.

Drijvers, P. (2015). Digital technology in mathematics education: Why it works (or doesn't). In S. Cho (Ed.), Selected Regular Lectures from the 12th International Congress on Mathematical Education (pp. 135151). Cham: Springer.

Duijzer, C., van den Heuvel-Panhuizen, M., Veldhuis, M., Doorman, M., \& Leseman, P. (2019). Embodied learning environments for graphing motion: A systematic literature review. Educational Psychology Review, 31, 597-629. 
Ellis, A., Tasova, H., \& Singleton, B. (2018). How quantitative reasoning can support graph understanding in algebra. In T. Hodges, G. Roy, \& A. Tyminski (Eds.), Proceedings of the 40th annual meeting of PME-NA (pp. 195-198). Greenville: University of South Carolina/Clemson University.

Goldin, G. (2000). A scientific perspective on structured, task-based interviews in mathematics education research. In A. Kelly \& R. Lesh (Eds.), Handbook of research design in mathematics and science education (pp. 517-545). Mahwah: Lawrence Erlbaum Associates.

Janvier, C. (1998). The notion of chronicle as an epistemological obstacle to the concept of function. The Journal of Mathematical Behavior, 17(1), 79-103.

Johnson, H. (2015). Together yet separate: Students' associating amounts of change in quantities involved in rate of change. Educational Studies in Mathematics, 89(1), 89-110.

Johnson, H., \& McClintock, E. (2018). A link between students' discernment of variation in unidirectional change and their use of quantitative variational reasoning. Educational Studies in Mathematics, 97(3), 299-316.

Johnson, H., Coles, A., \& Clarke, D. (2017a). Mathematical tasks and the student: Navigating "tensions of intentions" between designers, teachers, and students. ZDM: The International Journal on Mathematics Education, 49(6), 813-822.

Johnson, H., McClintock, E., \& Hornbein, P. (2017b). Ferris wheels and filling bottles: A case of a student's transfer of covariational reasoning across tasks with different backgrounds and features. ZDM: The International Journal on Mathematics Education, 49(6), 851-864.

Kaput, J. (1994). Democratizing access to calculus: New routes to old roots. In A. Schoenfeld (Ed.), Mathematical thinking and problem solving (pp. 77-156). Mahwah, Lawrence Erlbaum Associates.

Kaput, J. (1998). Representations, inscriptions, descriptions and learning: A kaleidoscope of windows. The Journal of Mathematical Behavior, 17(2), 265-281.

Kaput, J., \& Roschelle, J. (1999). The mathematics of change and variation from a millennial perspective: New content, new context. In C. Hoyles, C. Morgan, \& G. Woodhouse (Eds.), Rethinking the mathematics curriculum (pp. 155-170). London: Falmer Press.

Kerslake, D. (1977). The understanding of graphs. Mathematics in School, 6(2), 22-25.

Kitchen, R., \& Berk, S. (2016). Educational technology: An equity challenge to the common core. Journal for Research in Mathematics Education, 47, -(1), 3-16.

Kullberg, A., Runesson Kempe, U., \& Marton, F. (2017). What is made possible to learn when using the variation theory of learning in teaching mathematics? ZDM: The International Journal on Mathematics Education, 49(4), 559-569.

Leinhardt, G., Zaslavsky, O., \& Stein, M. (1990). Functions, graphs, and graphing: Tasks, learning, and teaching. Review of Educational Research, 60, -(1), 1-64.

Lobato, J., Walters, C., Walker, D., \& Voigt, M. (2019). How do learners approach dialogic, on-line mathematics videos? Digital Experiences in Mathematics Education, 5(1), 1-35.

Marton, F. (2014). Necessary conditions of learning. New York: Routledge.

Moore, K. (2016). Graphing as figurative and operative thought. In C. Csíkos, A. Rausch, \& J. Szitányi (Eds.), Proceedings of the 40th Conference of the International Group for the Psychology of Mathematics Education (Vol. 3, pp. 323-330). Szeged: PME.

Moore, K., \& Thompson, P. (2015). Shape thinking and students' graphing activity. In T. Fukawa-Connelly, N. Infante, R. Keene, \& M. Zandieh (Eds.), Proceedings of the 18th Meeting of the MAA Special Interest Group on Research in Undergraduate Mathematics Education (pp. 782-789). Pittsburgh: RUME.

Moore, K., Paoletti, T., \& Musgrave, S. (2013). Covariational reasoning and invariance among coordinate systems. The Journal of Mathematical Behavior, 32(3), 461-473.

Moore, K., Silverman, J., Paoletti, T., \& LaForest, K. (2014). Breaking conventions to support quantitative reasoning. Mathematics Teacher Educator, 2(2), 141-157.

Moore, K., Stevens, I., Paoletti, T., Hobson, N. \& Liang, B. (2019). Pre-service teachers' figurative and operative graphing actions. The Journal of Mathematical Behavior, 56.

Patterson, C. L., \& McGraw, R. (2018). When time is an implicit variable: An investigation of students' ways of understanding graphing tasks. Mathematical Thinking and Learning, 20(4), 295-323.

Schorr, R., \& Goldin, G. (2008). Students' expression of affect in an inner-city SimCalc classroom. Educational Studies in Mathematics, 68(2), 131-148.

Simon, M., Tzur, R., Heinz, K., \& Kinzel, M. (2004). Explicating a mechanism for conceptual learning: Elaborating the construct of reflective abstraction. Journal for Research in Mathematics Education, 35(5), 305-329.

Steffe, L., \& Thompson, P. (2000). Teaching experiment methodology: Underlying principles and essential elements. In A. Kelly \& R. Lesh (Eds.), Research design in mathematics and science education (pp. 267306). Mahwah: Lawrence Erlbaum Associates. 
Thompson, P. (1994). The development of the concept of speed and its relationship to concepts of rate. In G. Harel \& J. Confrey (Eds.), The development of multiplicative reasoning in the learning of mathematics (pp. 179-234). Albany: SUNY Press.

Thompson, P. (2002). Didactic objects and didactic models in radical constructivism. In K. Gravemeijer, R. Lehrer, B. van Oers, \& L. Verschaffel (Eds.), Symbolizing, modeling and tool use in mathematics education (pp. 197-220). Dordrecht: Kluwer Academic Publishers.

Thompson, P. (2011). Quantitative reasoning and mathematical modeling. In S. Chamberlain \& L. Hatfield (Eds.), New perspectives and directions for collaborative research in mathematics education: Papers from a planning conference (pp. 33-56). Laramie: University of Wyoming.

Thompson, P. (2012). Advances in research on quantitative reasoning. In R. Mayes, R. Bonillia, L. Hatfield, \& S. Belbase (Eds.), Quantitative reasoning: Current state of understanding (pp. 143-148). Laramie: University of Wyoming.

Thompson, P., \& Carlson, M. (2017). Variation, covariation, and functions: Foundational ways of thinking mathematically. In J. Cai (Ed.), Compendium for research in mathematics education (pp. 421-456). Reston: NCTM.

Vitale, J., Applebaum, L., \& Linn, M. (2019). Coordinating between graphs and science concepts: Density and buoyancy. Cognition and Instruction, 37(1), 38-72.

Publisher's Note Springer Nature remains neutral with regard to jurisdictional claims in published maps and institutional affiliations. 